\title{
RETROSPECTO DE OCORRÊNCIAS DE VIOLÊNCIA CONTRA A MULHER UM REGISTRADAS EM UMA DELEGACIA ESPECIAL*
}

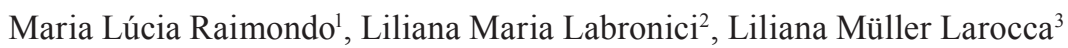

RESUMO: Pesquisa quantitativa descritiva e retrospectiva objetivou delinear o perfil da violência perpetrada contra a mulher em um município paranaense. Os dados foram obtidos em 4.478 Boletins de Ocorrência e Termos Circunstanciados lavrados na Delegacia da Mulher, de 2005 a 2009. A análise se deu pela estatística descritiva. Os resultados evidenciaram que 93,4\% das vítimas residiam na zona urbana; 82,8\% tinham entre 20 e 59 anos; 54,2\% viviam em união estável; 69,4\% possuíam ensino fundamental; $52,7 \%$ desenvolviam atividade remunerada. 70,1\% das violências ocorreram dentro de casa e as mais frequentes foram psicológica e física. Os principais agressores eram familiares, em especial cônjuges; $20,9 \%$ dos agressores usavam álcool ou drogas. A violência é um problema presente no cotidiano das mulheres do município e o delineamento de seu perfil revela-se importante ferramenta para o planejamento de políticas e ações, com vistas a sua erradicação.

DESCRITORES: Enfermagem; Saúde da mulher; Violência contra a mulher; Violência doméstica.

\section{A RETROSPECTIVE STUDY OF OCCURRENCES OF VIOLENCE AGAINST WOMEN RECORDED IN A SPECIALISED POLICE UNIT}

\begin{abstract}
This quantitative, descriptive and retrospective research aimed to outline the profile of violence perpetrated against women in a municipality in the state of Paraná. The data was obtained from 4,478 Police Reports and Minor Incidents recorded in the Women's Protection Police Unit, between 2005 and 2009. Analysis was undertaken through descriptive statistics. The results evidenced that $93.4 \%$ of the victims reside in the urban area; that $82.8 \%$ were aged between 20 and 59 years old; that $54.2 \%$ live in a stable relationship; that $69.4 \%$ had finished basic education; and that $52.7 \%$ carried out paid work. $70.1 \%$ of the incidents of violence took place within the home, and the most frequent forms were psychological and physical. The main aggressors were family members, especially spouses; $20.9 \%$ of the aggressors used alcohol or drugs. Violence is a problem present in the daily life of the women in the municipality, and outlining its profile is shown to be an important tool for planning policies and actions, with a view to its eradication. DESCRIPTORS: Nursing; Women's health; Violence against women; Domestic violence.
\end{abstract}

\section{RETROSPECTO DE OCURRENCIAS DE VIOLENCIA CONTRA LA MUJER REGISTRADAS EN UNA DELEGACIÓN ESPECIAL}

RESUMEN: Investigación cuantitativa descriptiva y retrospectiva cuyo objetivo fue delinear el perfil de la violencia perpetrada contra la mujer en un municipio paranaense. Los datos fueron obtenidos en 4.478 "Boletines de Ocurrencia" y "Términos Registrados en la Delegación de la Mujer, de 2005 a 2009. El análisis fue hecho por medio de estadística descriptiva. Los resultados evidenciaron que $93,4 \%$ de las víctimas vivían en la zona urbana; 82,8\% tenían entre 20 y 59 años; 54,2\% vivían en unión estable de pareja; $69,4 \%$ poseían enseñanza fundamental; $52,7 \%$ desarrollaban actividad remunerada. $70,1 \%$ de las violencias ocurrieron dentro en la propia casa y las más frecuentes fueron psicológica y física. Los principales agresores eran familiares, en especial cónyuges; 20,9\% de los agresores usaban álchool o drogas. La violencia es un problema presente en el cotidiano de las mujeres del municipio y la delineación de su perfil se revela importante herramienta para el planeamiento de políticas y acciones que objetivan su erradicación. DESCRIPTORES: Enfermería; Salud de la mujer; Violencia contra la mujer; Violencia doméstica.

*Artigo oriundo de dissertação apresentada ao Programa de Pós-Graduação em Enfermagem da Universidade Federal do Paraná PPGENF UFPR, em 2010.

${ }^{1}$ Enfermeira. Doutoranda pelo PGENF UFPR. Bolsista Fundação Araucária. Professora da Universidade Estadual do Centro-Oeste - UNICENTRO. Membro do Grupo de Estudos Multiprofissional em Saúde do Adulto - GEMSA e do Núcleo de Estudos e Pesquisa em Violência Urbana - NEVU.

${ }^{2}$ Enfermeira. Doutora em Enfermagem. Professora do Departamento de Enfermagem e do PPGENF UFPR. Líder do GEMSA.

${ }^{3}$ Enfermeira. Doutora em Educação. Professora do Departamento de Enfermagem e do PPGENF UFPR. Membro do Grupo de Pesquisas em Políticas, Gestão e Práticas de Saúde - GPPGPS.

Autor correspondente:

Recebido: $11 / 04 / 2012$

Liliana Maria Labronici

Aprovado: 30/01/2013

Universidade Federal do Paraná

R. Pref. Lothário Meissner, 632 - 80210-170 - Curitiba-PR-Brasil

E-mail: lililabronici@yahoo.com.br 


\section{INTRODUÇÃO}

A violência contra a mulher é um fenômeno silenciado ao longo da história, e passou a ser evidenciado no Brasil há, aproximadamente, 20 anos. Porém, em muitas sociedades ainda é visto de forma natural, como parte do cotidiano feminino, ou como um problema da família ${ }^{(1)}$. Sua manifestação se dá por meio de conflitos familiares, interpessoais e sociais, e a opressão, dominação e crueldade são algumas formas de sua manifestação que podem provocar danos físicos, sexuais, psicológicos, morais e patrimoniais.

Dados da Organização Mundial de Saúde revelam que uma em cada seis mulheres sofre violência doméstica no mundo ${ }^{(2)}$. No Brasil, uma pesquisa de base populacional, realizada com amostra representativa nacional de 2.502 mulheres evidenciou que $43 \%$ das brasileiras declararam ter sofrido violência em algum momento de sua vida. Esses dados permitiram aos pesquisadores inferir que um terço das mulheres brasileiras já foram vítimas de alguma forma de violência ${ }^{(3)}$.

Pesquisa realizada na capital paranaense demonstrou que, em média, 63 mulheres anualmente são obrigadas a deixar o convívio social e familiar em busca de assistência e proteção em uma casa abrigo, por consequência das agressões ou ameaças que colocam a vida em risco ${ }^{(4)}$. Estima-se que a violência praticada contra mulheres adultas seja responsável por mais mortes que câncer, malária, acidentes de trânsito e guerras. Os agressores geralmente são pessoas que convivem no domicílio, ou que exercem relações de poder sobre a vítima ${ }^{(5)}$.

Por ferir os direitos humanos e provocar agravos à saúde das mulheres, a violência passou a ser reconhecida como um problema de saúde pública. Assim, suscita medidas políticas de intervenção social, com ações de caráter interdisciplinar e intersetorial, compondo-se de redes de assistência à saúde, à segurança pública e pessoal, à justiça e ao bem estar social ${ }^{(5)}$. Neste sentido, os profissionais que atuam na área da saúde, entre eles o enfermeiro, devem estar capacitados para identificar os casos de violência, detectar riscos, assistir e acompanhar mulheres vitimizadas.

O enfermeiro deve refletir sobre o planejamento do cuidado às vítimas de violência, pautando-se nos instrumentos básicos de Enfermagem, nas políticas públicas de saúde e na legislação vigente. Este deve ser planejado com vistas a promover segurança, acolhimento, respeito e satisfação das necessidades individuais e sociais desta população ${ }^{(6)}$.
A delimitação do perfil da violência revela-se uma importante ferramenta de que a Enfermagem poderá lançar mão para o planejamento de ações de cuidado às vítimas de violência, uma vez que possibilita ${ }^{(7)}$ : analisar a distribuição dos fatores determinantes do processo saúde-doença, fixar a distribuição de agravos à saúde, identificar grupos vulneráveis para fins de prevenção e gerar hipóteses etiológicas para investigações futuras. A visibilidade do perfil deste agravo aos setores de segurança, poder judiciário, saúde e profissionais que nele trabalham, bem como para sociedade como um todo, poderá ser o ponto de partida para a erradicação deste agravo que acomete milhares de mulheres ${ }^{(4)}$.

Considerando a relevância do tema, a pesquisa teve como objetivo delinear o perfil da violência perpetrada contra a mulher em um município do Estado do Paraná.

\section{MÉTODO}

Trata-se de pesquisa quantitativa descritiva retrospectiva, desenvolvida na Delegacia da Mulher de um município de médio porte da região central do Estado do Paraná. Os dados foram obtidos com base em 4.478 Boletins de Ocorrência (BO) e Termos Circunstanciados (TC), de mulheres vítimas de violência em todas as faixas etárias, elaborados na Delegacia do município, no período de 1 de janeiro de 2005 a 31 de dezembro de 2009, correspondendo ao total de registros disponibilizados para consulta.

A coleta dos dados ocorreu de novembro de 2009 a abril de 2010, mediante formulário estruturado, elaborado a partir das informações contidas nos BO e TC, e que foi previamente testado com base em documentos de anos anteriores ao período delimitado para a pesquisa.

A inclusão dos dados em planilha eletrônica foi realizada por dupla digitação, e para a análise utilizaram-se procedimentos da estatística descritiva, com auxilio do programa computacional Statistica v.8.0. Na variável idade calculou-se também a média e desvios padrão. O coeficiente de reincidência de violência foi calculado a partir do número de vezes que a mesma mulher foi violentada.

No que se refere aos aspectos éticos, a pesquisa foi aprovada pelo Comitê de Ética do Setor de Ciências da Saúde da Universidade Federal do Paraná (Registro CEP/SD/UFPR: 783.118.09.08 - CAAE 3024.0.000.091-09). 


\section{RESULTADOS}

A análise do total de casos registrados no período de 2005 a 2009 evidenciou o registro de 895 casos/ ano, 74 casos/mês, o que equivale a aproximadamente 2 casos/dia; $82,9 \%$ das vítimas registraram um único episódio de violência, todavia, $17,1 \%$ foram reincidentes e efetuaram de dois a seis registros de violência. Entre as vítimas, $4.181(93,4 \%)$ residiam na zona urbana do município, enquanto que $297(6,6 \%)$ na zona rural. A idade das mulheres vitimizadas pela violência variou entre $1 \mathrm{e}$ 87 anos, com média de 32,8 anos ( $\mathrm{DP}=12,6)$. A maioria $(82,8 \%)$ tinha entre 20 a 59 anos; $13,7 \%$ adolescentes; $2,7 \%$ idosas e $0,8 \%$ crianças. No que se refere à situação conjugal, $54,2 \%$ viviam em união estável; $21,8 \%$ eram solteiras; $20,4 \%$ separadas e $3,6 \%$ viúvas.

A baixa escolaridade prevaleceu entre 3.223 (72\%) vítimas. Do total, 2.054 (45,9\%) possuíam ensino fundamental incompleto; 1.054 (23,5\%) fundamental completo e $117(2,6 \%)$ eram analfabetas. O ensino médio foi cursado por $998(22,3 \%)$ mulheres vítimas e o ensino superior entre 125 (2,8\%); apenas uma possuía pós-graduação. $\mathrm{O}$ trabalho remunerado era exercido por $2.359(52,7 \%)$ mulheres e, $2.019(47,3 \%)$ eram financeiramente dependentes, vez que desenvolviam atividades não remuneradas dentro de seus próprios lares ou eram estudantes.

Em $3.140(70,1 \%)$ casos a violência foi praticada no ambiente doméstico e 1.338 (29,9\%) em vias públicas ou locais de lazer. A violência psicológica esteve presente em 1.965 (43,9\%) ocorrências, a física em $1.711(38,2 \%)$ e a moral em $598(13,4 \%)$. Em menor proporção ocorreu violência sexual, com $143(3,2 \%)$ casos e patrimonial em $61(1,3 \%)$ casos. A maior frequência da violência ocorreu no período noturno, entre 18:00 e 24:00 horas $(43,3 \%)$, e no vespertino entre 12:00 e 18:00 horas (29,5\%).

Em 2.866 (64\%) casos a violência foi praticada por familiares ou pessoas de convívio doméstico, como marido, filhos, irmãos, pais, padrasto, tio, cunhado e namorado, e foi caracterizada como violência doméstica/familiar. Nos 1.612 (36\%) casos restantes estiveram envolvidos vizinhos, colegas ou pessoas desconhecidas, e foi considerada como violência comunitária.

Os meios empregados para a prática da violência foram: verbalização de xingamentos, injúrias e ameaças ( $45,4 \%)$; força corporal baseada em tapas, socos, chutes, estrangulamentos e puxões $(25,5 \%)$, utensílios e objetos domésticos como vassoura, cadeira, ferro de passar, copo, controle remoto (16,1\%); armas branca e de fogo como facas, tesouras, facões, canivetes, machado, serrote, foice, revólver, espingarda e pistola (7,8\%). Além dos instrumentos já apresentados, encontrou-se ainda $(5,2 \%)$ : pedra, barra de ferro, corda, corrente, cinto, pedaço de madeira, caco de vidro, fósforo e álcool, para atear fogo à vítima.

Em $71,1 \%$ dos casos o consumido de substâncias tóxicas não foi citado como presente no momento da agressão. O álcool foi evidenciado em $18,1 \%$ dos casos, enquanto as drogas como crack, cocaína e maconha em 1,6\%, e a associação de ambas em 1,2\%.

A tabela 1 evidencia que em 2007 e 2008 ocorreu pequena elevação no número de casos de violência registrados. Todavia, em 2009 os números decresceram novamente, mantendo índices semelhantes aos de 2005 e 2006. A violência física foi mais prevalente nos anos iniciais, e menos nos anos finais da série estudada. A psicológica, por sua vez, apresentou padrão inverso.

Na tabela 2 destacam-se os motivos apresentados pelas vítimas para o desfecho da violência, em relação ao tipo de violência. A discussão foi o motivo mais citado, e esteve presente em $26,4 \%$ dos casos, e mais prevalente na violência física $(30,5 \%)$ e na psicológica $(25,8 \%)$. O comportamento agressivo foi o segundo motivo mais citado $(15,5 \%)$, e também foi mais frequente na violência física $(21,6 \%)$ e na psicológica (15\%).

Tabela 1 - Tipo de violência perpetrada contra a mulher, segundo o ano de registro da ocorrência. Guarapuava, 2005 a 2009

\begin{tabular}{lcccccc}
\hline \multicolumn{7}{c}{ TIPO DE VIOLÊNCIA } \\
\hline $\begin{array}{l}\text { Ano de } \\
\text { ocorrência }\end{array}$ & $\begin{array}{c}\text { Física } \\
\mathbf{n}(\%)\end{array}$ & $\begin{array}{c}\text { Psicológica } \\
\mathbf{n}(\%)\end{array}$ & $\begin{array}{c}\text { Sexual } \\
\mathbf{n}(\%)\end{array}$ & $\begin{array}{c}\text { Patrimonial } \\
\mathbf{n}(\%)\end{array}$ & $\begin{array}{c}\text { Moral } \\
\mathbf{n}(\%)\end{array}$ & $\begin{array}{c}\text { Total } \\
\mathbf{n}(\%)\end{array}$ \\
\hline 2005 & $323(38,9)$ & $358(43,1)$ & $32(3,9)$ & $8(1,0)$ & $110(13,2)$ & $831(18,6)$ \\
2006 & $374(43,9)$ & $332(39,0)$ & $30(3,5)$ & $8(0,9)$ & $108(12,7)$ & $852(19,0)$ \\
2007 & $365(37,5)$ & $427(43,8)$ & $20(2,1)$ & $18(1,8)$ & $144(14,8)$ & $974(21,7)$ \\
2008 & $335(35,3)$ & $434(45,7)$ & $36(3,8)$ & $13(1,4)$ & $131(13,8)$ & $949(21,2)$ \\
2009 & $314(36,0)$ & $414(47,5)$ & $25(2,9)$ & $14(1,6)$ & $105(12)$ & $872(19,5)$ \\
Total & $1711(38,2)$ & $1965(43,9)$ & $143(3,2)$ & $61(1,3)$ & $598(13,4)$ & $4478(100)$ \\
\hline
\end{tabular}


Tabela 2 - Motivos que levaram ao desfecho da violência, segundo o tipo de violência sofrida pelas mulheres. Guarapuava, 2005 a 2009

\begin{tabular}{lcccccc}
\hline & \multicolumn{7}{c}{ TIPO DE VIOLÊNCIA } \\
\hline $\begin{array}{l}\text { Motivos para } \\
\text { o desfecho da } \\
\text { violência }\end{array}$ & $\begin{array}{c}\text { Física } \\
\mathbf{n}(\%)\end{array}$ & $\begin{array}{c}\text { Psicológica } \\
\mathbf{n}(\%)\end{array}$ & $\begin{array}{c}\text { Sexual } \\
\mathbf{n}(\%)\end{array}$ & $\begin{array}{c}\text { Patrimonial } \\
\mathbf{n}(\%)\end{array}$ & $\begin{array}{c}\text { Moral } \\
\mathbf{n}(\%)\end{array}$ & $\begin{array}{c}\text { Total } \\
\mathbf{n}(\%)\end{array}$ \\
\hline $\begin{array}{l}\text { Discussão } \\
\text { Comportamento }\end{array}$ & $522(30,5)$ & $508(25,8)$ & $6(4,2)$ & $18(29,5)$ & $129(21,6)$ & $1183(26,4)$ \\
$\begin{array}{l}\text { agressivo } \\
\text { Rompimento }\end{array}$ & $1670(21,6)$ & $294(15,0)$ & $7(4,9)$ & $9(14,8)$ & $14(2,3)$ & $694(15,5)$ \\
da relação & & & & & & \\
$\begin{array}{l}\text { Injúria e/ou } \\
\text { difamação }\end{array}$ & $63(3,7)$ & $178(9,1)$ & $1(0,7)$ & $2(3,3)$ & $301(50,3)$ & $545(12,2)$ \\
$\begin{array}{l}\text { Uso de álcool } \\
\text { e/ou drogas }\end{array}$ & $268(15,7)$ & $183(9,3)$ & $3(2,1)$ & $6(9,8)$ & $38(6,4)$ & $498(11,1)$ \\
Ciúmes & $206(12,0)$ & $206(10,5)$ & - & $3(4,9)$ & $42(7,0)$ & $457(10,2)$ \\
Sexual* & $100(5,8)$ & $108(5,5)$ & $112(78,3)$ & $2(3,3)$ & $13(2,2)$ & $335(7,5)$ \\
Outros & $15(0,9)$ & $38(1,9)$ & $10(7,0)$ & $7(11,5)$ & $10(1,7)$ & $80(1,8)$ \\
Total & $1711(100)$ & $1965(100)$ & $143(100)$ & $61(100)$ & $598(100)$ & $4478(100)$ \\
\hline
\end{tabular}

* Motivo sexual: estupro - tentativa de estupro - atentado violento ao pudor, assédio sexual, recusa da esposa/companheira em manter relação sexual com seu parceiro

\section{DISCUSSÃO}

Os achados do estudo revelam que mensalmente, em média, 74 mulheres foram vítimas de violência e denunciaram seus agressores no município. Entretanto, os números tendem a não retratar a real situação da violência no município, visto que de acordo com o Ministério da Saúde apenas 10\% das brasileiras vitimizadas pela violência registram as agressões no sistema judiciário ou de saúde, resultando em subnotificação estimada de $90 \%{ }^{(8)}$.

A reincidência de violência foi observada em $17,1 \%$ dos registros analisados, contrapondo-se ao evidenciado em estudo realizado em serviços da rede pública de saúde da Grande São Paulo, onde 58,6\% das mulheres referiram haver sofrido episódios repetitivos de violência durante a vida, porém não a notificaram. A violência repetitiva apresenta agravos à saúde das mulheres, levando-as a buscar os serviços de saúde com maior freqüência ${ }^{(9)}$.

A análise do número de casos de violência em relação à população feminina residente nas zonas urbana e rural do município, de acordo com os dados divulgados em 2007 pelo Instituto Brasileiro de Geografia e Estatístiva - IBGE, revelou que no universo feminino residente na zona urbana, 5,9\% sofreu violência e denunciou seus agressores. Já entre a população feminina residente na zona rural este percentual foi de $2,3 \%$. Desta forma, as mulheres da zona rural sofreram menos violência que as da urbana, ou então, denunciaram menos seus agressores. Os achados contrapõem-se ao evidenciado em uma pesquisa desenvolvida pela Organização Mundial da Saúde em diversos países do mundo, entre eles o Brasil, onde observou que as mulheres da área rural sofrem mais violência que as da área urbana ${ }^{(2)}$. Desta forma, a menor notificação pelas residentes na zona rural deve ser motivo de preocupação e investigações.

A violência perpassou todas as faixas etárias, e atingiu de crianças até mulheres idosas, porém, afetou majoritariamente mulheres adultas jovens, e esta é uma realidade encontrada por estudiosos em várias regiões do Brasil. A exemplo, tem-se um estudo desenvolvido em São Paulo que também evidenciou a vulnerabilidade das mulheres mais jovens em $67,7 \%$ dos $\operatorname{casos}^{(9)}$. Esta realidade denota maior atenção de gestores e profissionais no planejamento de ações de enfrentamento.

Durante a realização desta pesquisa observou-se que a maioria dos estudos encontrados não aborda a violência sofrida por crianças, adolescentes e idosas como parte integrante da violência contra a mulher. Todavia, há que se destacar que, a violência não se restringe à vitimização daquelas em idade jovem, no 
período reprodutivo, como retrata a maioria dos trabalhos, ao contrário, inicia na infância, continua ao longo da vida adulta e assume novas formas na velhice ${ }^{(10)}$. Nesse sentido, devem fazer parte dos estudos e das ações de detecção, proteção e prevenção.

Para compreender a violência se faz necessário conhecer suas várias faces, pois este é um fenômeno que acompanha as mulheres em todas as fases da vida. Esta declaração foi constatada em estudo desenvolvido na região Nordeste brasileira, na qual $39,7 \%$ das mulheres adultas vítimas de violência afirmaram já terem vivenciado a violência também na infância ou adolescência ${ }^{(11)}$.

Uma parcela significativa de mulheres vivia em união estável, possuía baixa escolaridade e desenvolvia atividade remunerada, porém, quase a metade das vítimas $(47,3 \%)$, era financeiramente dependente do cônjuge ou de outros familiares, que na maioria das vezes eram os agressores. Fato esse que pode favorecer a relação de submissão da vítima ao agressor, obrigando-a a permanecer no ciclo da violência. A dependência financeira entre uma parcela significativa também foi constatada entre vítimas de violência atendidas em um serviço de Pronto-socorro de Teresina - Piauí, onde $40 \%$ desenvolviam atividades sem remuneração dentro de suas casas ${ }^{(12)}$.

A realidade constatada nos estudos revela que, apesar dos avanços e conquistas em relação aos direitos das mulheres, uma importante parcela ainda vive na condição de domesticação imposta no período colonial brasileiro. Este modelo ainda se faz presente na sociedade atual, em que cabe a elas a responsabilidade exclusiva pelos afazeres domésticos e criação dos filhos. Neste sentido, enfrentar a violência contra as mulheres requer a conviç̧ão de que, para superá-la, é preciso investir no desenvolvimento de políticas que acelerem a redução das desigualdades sociais e de gênero ${ }^{(8)}$. Estudo desenvolvido com vítimas de violência em João Pessoa - Paraíba ${ }^{(13)}$, revelou o trabalho remunerado e a independência financeira das mulheres como importante condição para a transformação da realidade vivida e libertação das amarras da violência por elas vivida dentro de casa ${ }^{(13)}$.

Quanto ao local onde aconteceu a violência, observou-se que $70,1 \%$ das vítimas foram violentadas dentro de suas próprias casas. Esta realidade também foi encontrada em um estudo desenvolvido em Araçatuba, São Paulo, onde 89,3\% das participantes foram vitimizadas pela violência dentro de suas $\operatorname{casas}^{(14)}$. Desta forma, é possível constatar a perda da referência do espaço privado e familiar como sinônimo de segu- rança para as mulheres. Assim, vive-se um momento em que não há proteção, pois a violência tem invadido todos os espaços da sociedade, inclusive aqueles que se acreditava ter domínio ${ }^{(15)}$.

No município onde se desenvolveu o estudo, a violência contra a mulher, majoritariamente, foi cometida por membros da própria família, principalmente por maridos ou companheiros, caracterizando-se como violência doméstica/familiar. Estudo refere que as mulheres são humilhadas, estupradas e, muitas vezes, assassinadas por seus próprios companheiros, e, com frequência, por ex-companheiros dentro de suas próprias casas $^{(16)}$. Neste sentido, a violência doméstica conjugal, perpetrada pelo parceiro íntimo, tem sido a principal forma de violência sofrida pela população feminina.

Importante se faz destacar que a violência comunitária também ocupou um espaço significativo na vida destas mulheres, estando em situação de risco dentro e fora de casa. Neste sentido, as mulheres são duplamente vítimas de situações violentas, porque como cidadãs se defrontam com as diversas formas de violência que afetam a sociedade brasileira na atualidade, e como mulheres vivenciam a violência de gênero, que atinge milhares delas todos os dias dentro dos lares ${ }^{(8)}$.

A concentração dos casos de violência no horário entre 18:00 e 24:00 horas permite inferir que as primeiras horas da noite, quando os agressores retornam aos lares, são as que oferecem maior risco de violência para as mulheres. O predomínio da violência neste horário do dia também foi evidenciado em registros de ocorrência na Delegacia da Mulher de Araçatuba-São Paulo, em 40,8\% dos casos $^{(14)}$.

Menos de um quarto dos agressores estava sob seu efeito de substâncias lícitas (álcool) ou ilícitas (drogas) no momento em que praticaram a violência. Os resultados evidenciados assemelham-se ao de pesquisa desenvolvida em 108 cidades brasileiras, em que apenas $17,1 \%$ dos agressores estavam sob o seu efeito no momento da agressão ${ }^{(17)}$. Desta forma, o álcool não pode ser apontado como a causa desencadeante da violência, mas sim como um desinibidor do comportamento violento oculto no indivíduo. Assim sendo, isoladamente, seu uso não pode ser utilizado como justificativa para o comportamento violento, mas apenas precipitador ou agravante ${ }^{(12)}$.

As mulheres foram vítimas de todos os tipos de violência, porém, a psicológica foi a mais prevalente. Os meios mais utilizados por eles para a prática da violência foram a verbalização de palavrões, xingamentos ameaças e injúrias. A violência psicológica é 
mais praticada no interior dos lares, razão pela qual é silenciosa, pois sua reverberação acontece entre as paredes das casas, e se faz presente em todos os outros tipos de violência, porquanto interfere na integridade social, física e moral das mulheres ${ }^{(18)}$.

A violência perpetrada contra as mulheres no município estudado demonstrou pouca variação em suas taxas entre os anos de 2005 e 2009 . Esse padrão de regularidade observado permite atribuir à violência contra a mulher um status de problema de saúde pública de caráter endêmico, a ser combatido por meio de ações que envolvem detecção, assistência e prevenção ${ }^{(8)}$.

Os anos de 2007 e 2008, período imediato à promulgação e de intensa divulgação da Lei 11.340/2006 (Lei Maria da Penha), foram os que registraram maior ocorrência. A aprovação da referida Lei estimulou a inserção do tema violência contra as mulheres no cotidiano, e os meios de comunicação passaram a divulgar, de forma mais sistemática e qualificada, os casos de violência e os direitos das mulheres ${ }^{(8)}$, fato que deu visibilidade à violência e maior segurança às vítimas para denunciar seus agressores.

A distribuição dos casos de violência entre os cinco anos estudados permitiu constatar, que os tipos de violência praticados tiveram alterações nos padrões de manifestação. A partir de 2006, reduziram-se as violências comprováveis ao exame de corpo de delito, como a violência física, e elevaram-se as de difícil constatação, como a psicológica e a moral. Assim, o comportamento em relação ao tipo de violência se alterou com a Lei, porém, a sua prática não, porquanto o número de ocorrências registradas em cada ano foi semelhante. Esse fato denota a necessidade de implementar medidas não apenas relacionadas à punição, mas também à mudança do comportamento dos agressores.

\section{CONCLUSÃO}

A pesquisa permitiu constatar que a violência no município manteve uma linearidade em seus índices com pequena variação entre os anos estudados e atingiu todas as faixas etárias da vida das mulheres, porém as adultas jovens foram vítimas preferenciais. A maioria residia na zona urbana, era casada ou vivia em união estável, possuía baixo nível de escolaridade. Uma parcela significativa era financeiramente dependente, o que pode contribuir para que permaneçam no ciclo da violência.

As mulheres foram vítimas de todos os tipos de violência, contudo, a psicológica foi a mais prevalente, seguida da física, predominantemente praticada dentro da própria casa. Todavia, a violência comunitária também se fez presente, e os principais agressores foram os familiares, destacando-se os companheiros ou ex-companheiros. Os meios mais utilizados por eles foram a verbalização de palavrões, ameaças e injúrias, seguida da força corporal, muitas vezes acompanhadas de utensílios domésticos e armas. Menos de um quarto deles estava sob efeito de substâncias entorpecentes no momento em que praticou a violência.

Os dados desta pesquisa mostraram que apesar dos esforços conjuntos de setores públicos e sociais, com a implantação de Delegacias Especiais da Mulher, a promulgação da Lei 11.340/2006, a implantação de Políticas de atenção e erradicação da violência e das redes de atenção e apoio, a violência contra a mulher continua presente na realidade estudada. Essa constatação nos leva a refletir sobre a necessidade de abordar o tema nas escolas e universidades no sentido de promover mudanças culturais que promovam a igualdade de gênero e possibilite a resolução de conflitos sem o uso da violência.

Com base nestes resultados, observa-se a limitação deste estudo de se restringir a um município. Porém, a visibilidade do perfil deste agravo aos setores de segurança, judiciário, saúde e organizações sociais poderá subsidiar o planejamento do cuidado em saúde e a elaboração de estratégias de prevenção e de políticas de atenção a serem desenvolvidas pelos profissionais nas redes de atendimento, assegurando-se atendimento qualificado e humanizado às mulheres em situação de violência.

\section{REFERÊNCIAS}

1. Teles MAA, Melo M. O que é violência contra a mulher. São Paulo: Brasiliense; 2003.

2. Organização Mundial da Saúde. Relatório mundial sobre violência e saúde. Organização Genebra (Suíça): Organização Mundial da Saúde; 2002. [acesso em 20 out 2010]. Disponível: http://www.who.int/en

3. Venturi G, Recamán M. Sociedade: afinal, o que querem as mulheres? In: Venturi G; Recanan M, Oliveira S. A mulher brasileira nos espaços público e privado. São Paulo: Editora da Fundação Perseu Abramo; 2004.

4. Labronici LM, Ferraz MIR, Trigueiro TH, Fegadoli, D. Perfil da violência contra mulheres atendidas na Pousada de Maria. Rev Esc Enferm USP. 2010;44(1):126-33.

5. Schraiber LB, Oliveira AFPL, Falcão MTC, Figueredo WS. Violência dói e não é direito: a violência contra 
a mulher, a saúde e os direitos humanos. São Paulo: Editora da UNESP; 2005.

6. Ferraz MIR, Lacerda MR, Labronici LM, Maftum MA, Raimondo ML. O cuidado de enfermagem a vítimas de violência doméstica. Cogitare enferm. 2009;14(4):755-9.

7. Medronho RA. Epidemiologia. São Paulo: Atheneu; 2009.

8. Ministério da Saúde (BR). Secretaria Especial de Políticas para as Mulheres. Enfrentamento à violência contra a mulher: balanço de ações 2006-2007. Brasília: Ministério da Saúde; 2007.

9. Schraiber LB, Barros CRS, Castilho EA. Violência contra as mulheres por parceiros íntimos: usos de serviços de saúde. Rev. bras. epidemiol. 2010,13( 2):237-45.

10. Mota AB. Violência contra as mulheres idosas: questão feminista ou questão de gênero? In: Congresso da Latin American Studies Association. Rio de Janeiro, Brasil. Rio de Janeiro: LASA; 2009. p. 1-19 [acesso em 29 out. 2010]. Disponível: http://lasa.international.pitt.edu/ members/congress-papers/lasa2009/fst.asp

11. Silva MA, Falbo Neto GH, Figueiroa JN, Cabral Filho JE. Violence against women: prevalence and associated factors in patients attending a public healthcare service in the Northeast of Brazil. Cad. Saúde Pública. 2010;26(2):264-72.

12. Monteiro CFS, Araújo TME, Nunes BMVT, Lustosa AR, Bezerra CMJ. A violência contra a mulher atendida em unidade de urgência: uma contribuição da enfermagem. Esc. Anna Nery. 2006;10(2):273-9.

13. Guedes RN, Silva ATMC, Coelho EAC. Violência conjugal: problematizando a opressão das mulheres vitimizadas sob olhar de gênero. Rev. Eletr. Enf. [Internet] 2007;9(2) [acesso em 25 nov 2011]. Disponível: http://www.fen.ufg.br/revista/v9/n2/v9n2a06.htm

14. Dossi AP, Saliba O, Garbin CASG, Garbin AJI. Perfil epidemiológico da violência física intrafamiliar: agressões denunciadas em um município do Estado de São Paulo, Brasil, entre 2001 e 2005. Cad. Saude Publica. 2008;24(8):1939-52.

15. Santos AMF, Ramires JCL. Percepção espacial da violência e do medo pelos moradores dos bairros Morumbi e Luizote de Freitas em Uberlândia/MG. Soc. nat. 2009;21(1):131-45.

16. Saffioti HIB. Gênero e patriarcado: violência contra a mulher: In: In: Venturi G; Recanan M, Oliveira S. A mulher brasileira nos espaços público e privado. São Paulo: Editora da Fundação Perseu Abramo; 2004.

17. Fonseca AM, Galduroz JCF, Tondowski CS, Noto A. Alcohol-related domestic violence: a household survey in Brazil. Rev. Saúde Públ. 2009;43(5):743-9.

18. Ferreira WB, Pimentel A. Violência psicológica: as visíveis sequelas, no enfoque da Gestalt-terapia. In: Fazendo gênero 8. Florianópolis; 2008. [acesso em 16 nov 2011]; Disponível: http://www.fazendogenero8.ufsc.br 